\title{
EDITORIAL: NEW DEVELOPMENTS AND NEW DISCOURSE ON ARCHITECTURE AND URBAMISM
}

\author{
Ashraf M. Salama \\ Professor of Architecture, \\ Department of Architecture and Urban Planning, \\ Qatar University \\ asalama@qu.edu.qa
}

Over the past seven years and since Archnet-IJAR has published its first issue in March 2007 the journal has managed to position itself on the map of web publishing in architecture and urbanism. Following a comprehensive process of academic review of articles and research work submitted to the journal, it has succeeded to secure its position in various databases. One of the unique features of the Archnet-IJAR was, and still is, the voluntary work nature of its editors and reviewers where no funds are involved at all in managing or reviewing or editing the submissions before publishing. Another unique feature is that the journal since the beginning was, and still is, made available for free without subscription fees or publishing fees. A third feature of Archnet-IJAR is the opportunity it offers to young academics, $\mathrm{PhD}$ scholars, reaching across the boundaries of cultures and regions.

Key highlights in the past seven years are important to note. In qualitative and quantitative terms the journal has made significant achievements. In terms of quality the journal became part of important data and index bases including Avery index to Architectural Periodicals, EBSCO-Current Abstracts-Art and Architecture, INTUTE, Directory of Open Access Journals, Pro-Quest, ScopusElsevier and many university library databases. In terms of quantity 20 issues were published in 7 volumes (Figure 1). The 20 issues combined include 283 papers categorized in two categories: 237 original research articles and 46 book reviews and trigger articles. I should mention here that the issues produced by Archnet-IJAR cover almost every corner of the globe whether in terms of the context that they address or in terms of its authors' affiliations and cultural backgrounds.

At relatively regular intervals, the past seven years of the journals have witnessed the development of three important special issues that address topics of interest to the international community, listed below:

Vol 2, No 3 (2008)

Special Issue: Traditional Public Baths/Hammāms in the Mediterranean

Guest Editors: Magda Sibley and Fodil Fadli

http://www.archnet-ijar.net/index.php/IJAR/issue/view/15

Vol 4, No 2/3 (2010)

Special Issue: Design Education: Explorations and Prospects for a Better Built Environment Editors: Ashraf M. Salama and Michael J. Crosbie

http://www.archnet-ijar.net/index.php/IJAR/issue/view/16

Vol 7, No 3 (2013)

Special Issue: Post-Disaster Reconstruction

Guest Editors: Jason von Meding, Jamie Mackee and Thayaparan Gajendran

http://www.archnet-ijar.net/index.php/IJAR/issue/view/26

I have taken the sole responsibility in almost every single aspect of the journal from March 2007 until November 2011 when Remah Y. Gharib was involved as a volunteer Collaborating Editor. Through our joint effort was able to move forward with quality articles and timely and efficient completion of review and editorial tasks. 

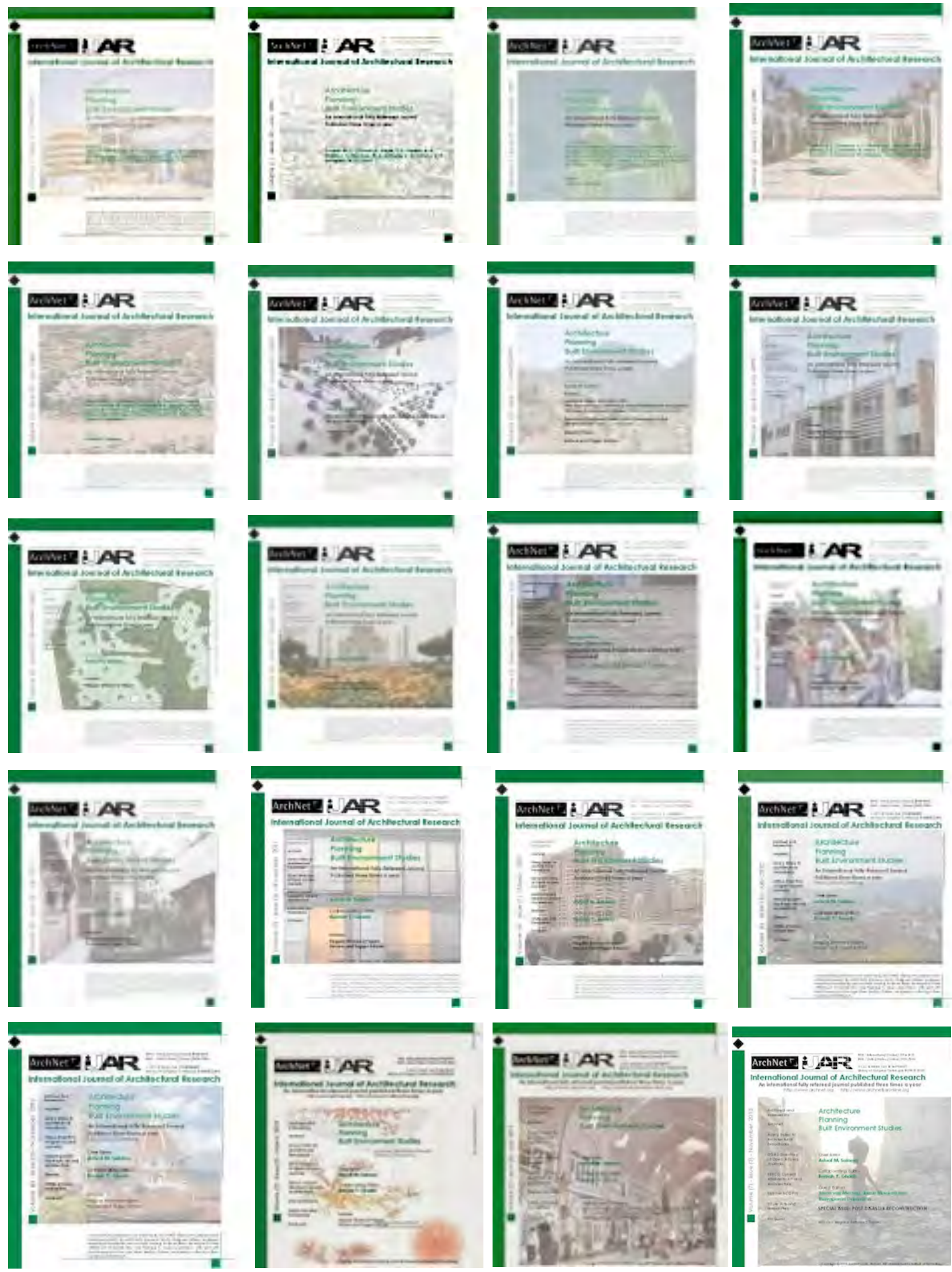

Figure 1: Archnet-IJAR Journal Covers from March 2007 to November 2014. 
Additionally, the breadth and depth of the issues covered throughout the years manifest the unique nature of the journal in terms of its openness to various types of academic and professional discourse. While this is evident in almost every single issue produced so far, the following is a list of feature articles that I should note in this context (click on the article to visit its page or download it).

- Alain Thierstein, Elisabeth Schein on Urban Space in the Knowledge Economy Context of the Arabian Peninsula

- Amos Rapoport on Further Thoughts on Culture and Environment

- Ann Forsyth on Interdisciplinary Research in Architecture

- Ashraf M. Salama on Integrating Knowledge in Design Pedagogy

- Bettina Kolb, Heidi Dumreicher on Traditional Public Baths as a Living Cultural Heritage

- Ceridwen Owen on Culture-Nature Dualism

- Henry Sanoff on Participatory Design

- Keith McAllister on Making the Design Process Relevant for Students

- Kheir Al-Kodmany, Mir M. Ali on Skyscrapers and Placemaking

- Krupali Uplekar Krusche et al. on the Morphology of Mughal Tombs

- Marta Alonso Provencio, Jorge Almazan on Scale Models in the Work of Kazuyo Sejima and Sou Fujimoto

- Michael J. Crosbie on Architecture Program's Use of Mission as a Pedagogical Roadmap

- Nikos A. Salingaros, Kenneth G. Masden II on Human Intelligence in 21st Century Architecture

- Núbia Bernardi, Doris C.C.K. Kowaltowski on Improved Universal Design Education

- Peter Kellett, Peter Collins on Competing Constructions of Hospital Environments

- Philip Plowright, Matthew Cole on Judging Success in Architectural Design

- Rahinah Ibrahim, Renate Fruchter, Roslina Sharif on Transdisciplinary Design Studio Education

- Richard Barrett on Establishing the Case for Daylighting in Architecture

- Sarah Lappin on Arts-Based Buildings and Cultural Policies

- Vincent B. Canizaro on Design-Build in Architectural Education

- Wolfgang F.E. Preiser, Stephen Verderber, Dina Battisto on Assessing Health Center Performance

Coupled with the new developments of Archnet, which was re-imagined and re-envisioned for scholars, students, and professionals (http://www.archnet.org), developed by the Aga Khan Trust for Culture in Association with Aga Khan Program for Islamic Architecture and the Aga Khan Documentation Center at MIT-Massachusetts of Technology, Cambridge, MA: USA, the journal had to develop an effective mechanism for receiving, reviewing, and archiving submissions. Therefore, the journal moved entirely to the OJS-Online Journal System where authors must register, for free, to submit their contributions. The same comprehensive double-blind review process is followed. As of this issue of March 2014 the journal has its own website where submissions, production, and archival take place http://www.archnet-ijar.net/ (Figure 2) and it is also featured and archived by Archnet http://archnet.org/collections/34 (Figure 3) part of its collection and resources. Here I should thank Shiraz Alibhai, Deputy General Manager of the Aga Khan Trust for Culture in Geneva for keeping the journal integral part of the important collection and resources of Archnet. Thanks are due to Sharon Smith, Program Head, Aga Documentation Center at MIT for making this happens.

As part of the new development of the journal an important addition to the team took place where Farzad Pour Rahimian is now a Collaborating Editor who works with me and Remah in managing and the technical aspects of the Online submission system in addition to his role as part of the International Review Board. 


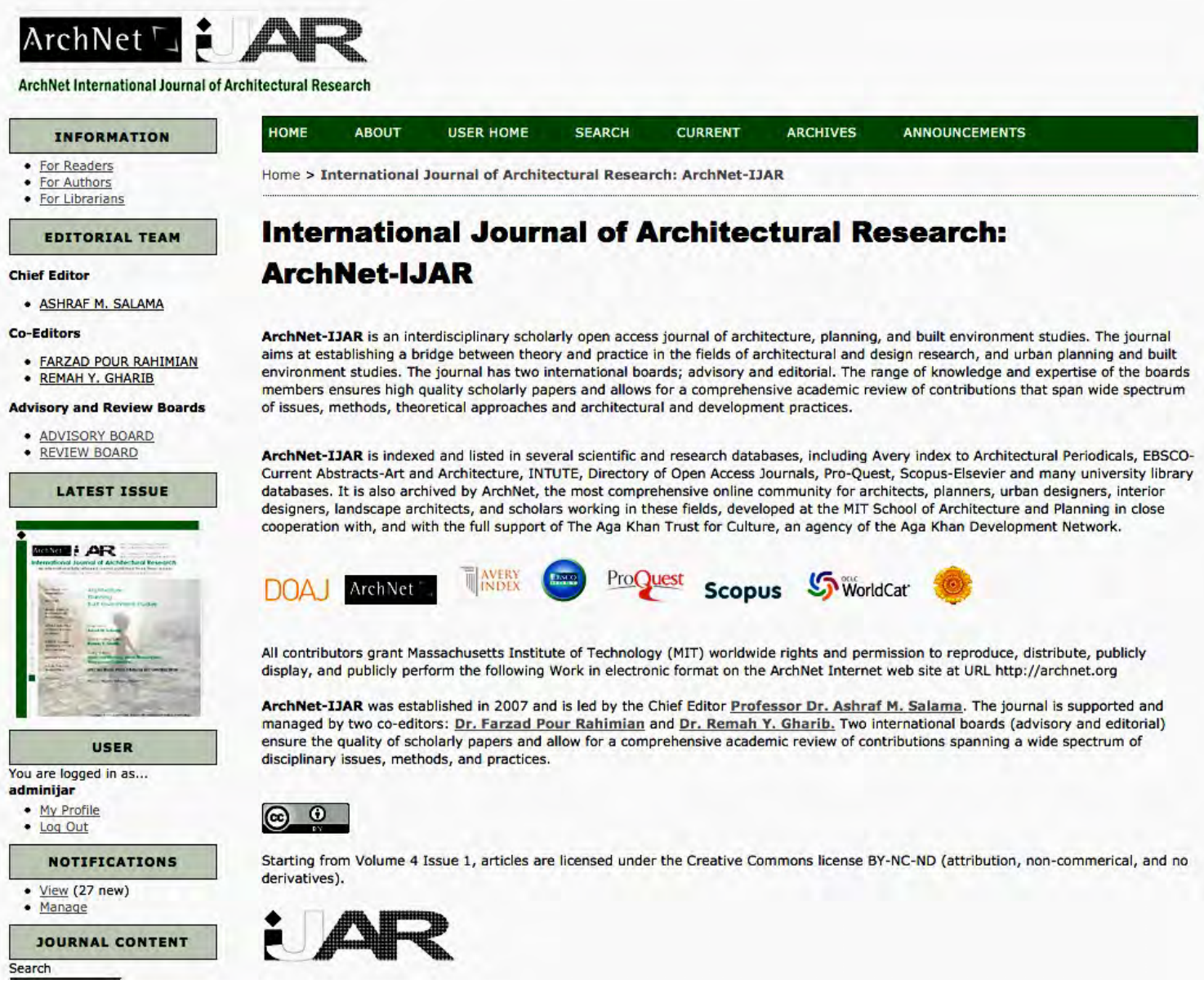

Figure 2: A screen image of the new website of the $\sim$ Archnet-IJAR-OJS (http://www.archnet-ijar.net/).

\begin{tabular}{|l|l|l|l|l|l|l|}
\hline ARCHNET & Research & Timeline & Collections & Resources & Syllabi & 0 \\
\hline
\end{tabular}

PUBUICATION SERIES

International Journal of Architectural Research [IJAR]

16 Lked: $34 \quad 2+$ Shared: 4

Established in 2007 INAR is an interdisciplinary, fully-refereed scholarly online journal of architecture, planning, and built environment studies and is edited by Ashraf $M$. Salama. Supported by two co-editors, Farzad Pour Rahimian and Remah Gharib, Salama. Supported by two co-editors, Farzad Pour Rahimian and Reman Gharib, JJAR
has two international boards (advisory and editorial) that ensure the quality of scholarly papers and allow for a comprehensive academic review of contributions spanning a wide spectrum of issues, methods, theoretical approaches and architectural and development practices. IJAR provides a comprehensive academic review of a wide spectrum of issues, methods, and theoretical approaches. It aims to bridge theory and practice in the fields of architectura//design research and urban planning/built environment studies, reporting on the latest research findings and innovative environment studies, reporting on the latest reseas
approaches for creatingresponsive environments.

To contribute please visit: IJAA

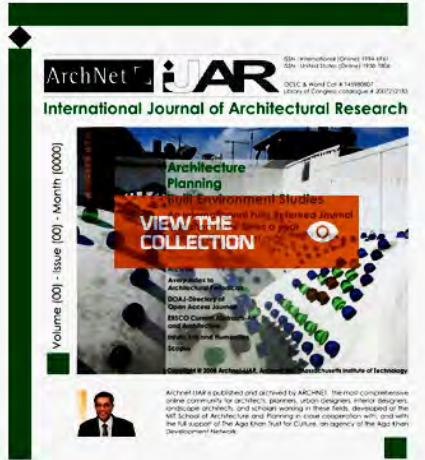

Figure 3: A screen image of Archnet-IJAR on the new website of Archnet (http://archnet.org/collections/34). 
Important developments and excellent additions to the International Advisory and Review Boards have taken place over the past few months, with more specializations added to the profile of Archnet-IJAR team. In the International Advisory Board Derya Oktay, Jack Steven Goulding, and Nezar AlSayyad are now part of the team offering guidance and expertise. In the International Review Board a number of distinguished scholars are part of the team including Ahad Ebrahimi, Amar Bennadji, Beatriz C. Maturana, Farzad Pour Rahimian, Florian Wiemann, Fodil Fadli, Jason Von Meding, Karim Hadji, Martina E Murphy, Rahinah Ibrahim, Remah Y. Gharib, Samer Bagaeen, Sarah A. Lappin, and Tomasz Arciszewski. I am pleased with this addition of dedicated academics. Their experience would enhance the review process. I must mention that I am also indebted to the members who helped shape the journal since its establishment.

This issue of IJAR marks the start of a new era for Archnet-IJAR and the beginning of its eighth volume. It includes this editorial, 11 original research articles, and 4 reviews and trigger articles. While some articles discuss universal issues that pertain to various contexts worldwide, articles come from 20 scholars covering many parts of the world including 9 countries including Australia, Bosnia, Egypt, Malaysia, Oman, Qatar, Turkey, United Kingdom, and United States. Articles include issues of relevance including the sustainable design aspects of tall buildings, health care architecture, traditional souqs and market places, meaning and socio-spatial practices, user comfort, and sustainable management of historic centers among other important issues.

I invite the worldwide academic architecture, urban design, and planning community to learn about the new website of Archnet-IJAR, look through its archives and collection on Archnet, and explore the articles of this issue. I also encourage young and budding academics to think of contributing quality papers to the journal based on their current research.

\author{
Author: \\ Ashraf M. Salama \\ Chief Editor of Archnet-IJAR \\ Professor of Architecture, \\ Department of Architecture and Urban Planning, \\ Qatar University \\ asalama@qu.edu.qa
}

